MAKALAH MODUL 3 PENDIDIKAN KEWARGANEGARAAN KETERKAITAN PENDIDIKAN KEWARGANEGARAAN DENGAN IPS DAN MATA PELAJARAN LAINNYA

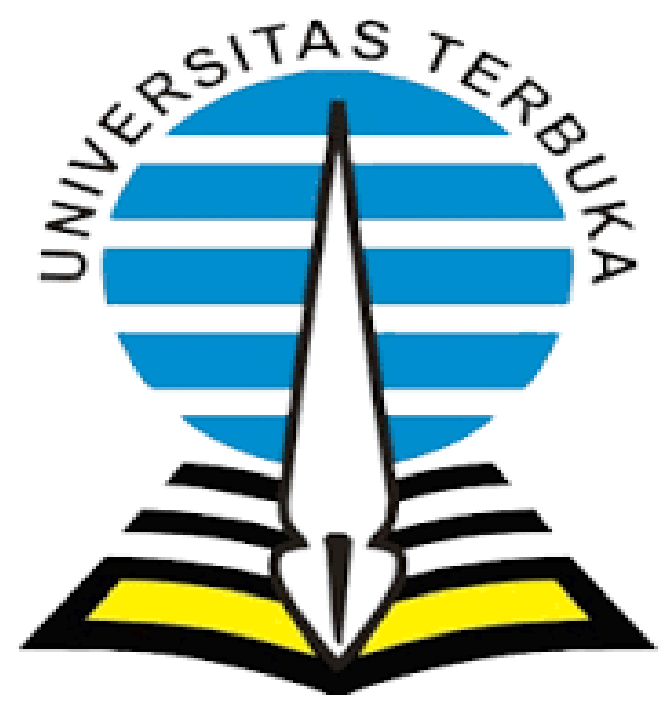

Disusun oleh :

KELOMPOK MODUL 3

NO NAMA MAHASISWA

1 ADI RAHARJO

2 NURJANAH DEWI SINTA

3 SAMIRAH
NIM

857300251

857300402

857300323

\title{
UNIVERSITAS TERBUKA
}

PROGRAM STUDI S.1 PGSD

TAHUN AJARAN 2019 


\section{BAB I}

\section{PENDAHULUAN}

\section{A. LatarBelakangMasalah}

Pendidikan Kewarganegaraandengan IPS dan matapelajaran lain memiliki keterkaitan. Dengan memahamihaltersebut, maka para guru SD dapatlebihmemperluaswawasansiswasiswa SD tentangketerkaitankeduamatapelajarantersebutataubahkanhubungannyadenganmata pelajaranlainnya. Hal itudimungkinkankarenaPendidikanKewarganegaraandan IPS berasaldarisaturumpunyaitumengenaiilmu-ilmusosial.

Agar

memahamiketerkaitanantaraPendidikanKewarganegaraandenganmatapelajaranlainn yamakaperludiketahuiterlebihdahulumengenaihakikatdankarakteristikPendidikanKe warganegaraanbegitujugadengankegiatanpembelajaranterpadu yang dapatditerapkanpadaPendidikanKewarganegaraan. Kemudian, setelahmengetahuikeduahaltersebut, makadiperlukanjugapengetahuantentang model pembelajaran yang tepat gar dapatmenghubungkanantarabidangstudiPendidikanKewarganegaraandengan Mata Pelajaranlainnyadengantepatsehinggasiswamudahdalammempelajarikonsep-konsep yang ada di berbagaimatapelajaran.

\section{B. RumusanMasalah}

Beberapamasalah yang akandibahasdalammakalahini, yaitusebagaiberikut:

1. BagaimanahakikatdankarakteristikPendidikanKewarganegaraan?

2. BagaimananketerkaitanPendidikanKewarganegaraandengan IPS?

3. Bagaimanakonseppembelajaranterpadu?

4. BagaimanaketerkaitanPendidikanKewarganegaraandenganmatapelaranlainnya?

\section{TujuanPenulisan}

Adapuntujuanpenulisanmakalahadalahsebagaiberikut:

1. UntukmengetahuihakikatdankarakteristikPendidikanKewarganegaraan.

2. UntukmengetahuiketerkaitanPendidikanKewarganegaraandengan IPS. 
3. Untukmengetahuikonseppembelajaranterpadu.

4. UntukmengetahuiketerkaitanPendidikanKewarganegaraandenganmatapelajaran lainnya.

\section{ManfaatPenulisan}

Adapunmanfaatdaripenulisanmakalahiniyaitusebagaisalahsatuacuandalamme mahamidanmenghubungkanantarabidangstudiPendidikanKewarganegaraandenganb idangstudi IPS danlainnyadalamkegiatanpembelajaran. 


\section{BAB II \\ PEMBAHASAN}

\section{KegiatanBelajar 1}

A. Gambaran Umum, Hakikat, dan Karakteristik Pendidikan Kewarganegaraan

1. Latar Belakang

Sejak diberlakukannya kurikulum sekolah tahun 1975, Pendidikan menjadi mata kuliah yang berdiri sendiri yang tujuaan umumnya adalah membentuk warga negara yang baik. Kemudian dalam perkembangannya. Kemudian dalam perkembangannya menjadi PMP (Pendidikan Moral Pancasila) yang sekarang dikenal dengan Pendidikan Kewarganegaraan. Kemudian berubah menjadi Pendidikan Pancasila dan Kewarganegaraan (PPKN) didasarkan UU RI no 2 tahun 1989.

PKn merupakan mata pelajaran yang sangat cepat perubahannya dikarenakan PKn rentan terhadap perubahan politik. Namun secara umum isi (hafalan), pendekatan (politis dan kekuasaan), dan penyampaiannya (satu arah/verbal) tidak banyak berubah.

2. Tujuan Pendidikan Kewarganegaraan

Di antara tujuan PKn adalah untuk mengembangkan kemampuankemampuan sebagai berikut:

a. Berpikir secara kritis, rasional, dan kreatif terhadap isu kewarganegaraan

b. Aktif, bertanggungjawab, dan cerdas dalam tindakan bermasyarkat, berbangsa, dan bernegara

c. Berkembang secara positif dan demokratis.

d. Berinteraksi dengan negara lain dengan memanfaatkan IPTEK

B. HakikatdanKarakteristikBidangStudiPendidikan

1. Hakikat Bidang Studi Pendidikan Kewarganegaraan

Hakikat Pendidikan kewarganegaraan adalah merupakan mata pelajaran yang memfokuskan pada pembentukan diri yang beragam dari segi agama, sosio-kultural, bahasa, usia, dan suku bangsa untuk menjadi warga negara 
Indonesia yang cerdas, terampil, dan berkarakter yang dilandasai Pancasila UUD 1945.

Oleh karena itu Bidang studi Pendidikan kewargenegaraan diajarkan kepada mahasiswa agar kelak nanti ketika menjadi guru dan mengajarkannya ke siswa SD, diharapkan agar siswa tersebut bukan hanya mengetahui dan menghayati tentang nilai-nilai moral Pancasila, namun dapat mengamalkan pengetahuan, sikap, dan perilaku tersebut sesuai dengan tingkat kematangan siswa SD.

2. Karakterististik Bidang Studi Pendidikan Kewarganegaraan

Mata pelajaran Pendidikan Kewarganegaraan menuntut lahirnya warga negara dan warga masyarakat yang Pancasila, yang beriman dan bertakwa kepada Tuhan Yang Maha Esa yang mengetahui hak dan kewajibannya, menyadari pentingnya melaksanakan kewajiban-kewajibannya yang didasari oleh ksadaran dan tanggungjawabnya sebagai warga negara, tidak mencemari air dan tidak merusak lingkungan.

Hal tersebut berhubungan dengan landasan konsep yang mendasari Pendidikan Kewarganegaraan yaitu manusia sebagai makhluk ciptaan Tuhan dan insan sosial politik yang terorganisasi dengan tujuan agar manusia Indonesia memiliki kemauan dan kemampuan untuk:

a. Sadar dan patuh terhadap hukum (melek hukum)

b. Sadar dan bertanggung jawab dalam kehidupan berbangsa dan bernegara (melek politik)

c. Memahami dan berpartisipasi dalam pembangunan nasional

d. Cinta bangsa dan tanah air.

Karakteristik Bidang Studi Pendidikan Kewarganegaraan yaitu sebagai suatu bidang kajian ilmiah dan program pendidikan di sekolah dan dapat diterima sebagai wahana utama serta esensi pendidikan demokrasi di Indonesia yang dilaksanakan melalui

a. Civic intelligence atau kecerdasan dan daya nalar warga.

b. Civic responsibility atau kesadaran hak dan kewajiban sebagai warga negara 
c. Civic participation atau kemampuan berpatisipasi baik indiividu, maupun sosial,

Ada 3 kompetensi yang hendak diwujudkan melalui mata pelajaran Pendidikan Kewarganegaraan

a. Kompetensi untuk menguasai pengetahuan kewarganegaraan

Tentang pemerintahan, konstitusi, dan hubungan luar negeri

b. Kompetensi untuk menguasai keterampilan kewarganegaraan

Tentang sikap dan pemecahan masalah

c. Kompetensi untuk menguasai karakter kewarganegaraan

Tentang penerapan nilai budi pekerti, demokrasi, ham, dan nasionalisme dalam kehidupan berbangsa dan bernegara.

C. Bidang studi Pendidikan Kewarganegaraan dalam kurikulum S1 PGSD

3. Pendidikan kewarganegaraan sebagai mata pelajaran SD

Landasan konsep yang mendasari pendidikan Kewarganegaran yaitu manusia adalah mahkluk ciptaan Tuhan dan sebagai insan sosial dan politik yang terorganisasi melahirkan fungsi dan peran serta tujuan pendidikan Kewarganegaraan.

Berdasarkan landasan konsep PKn tersebut, maka fungsi serta tujuan PKn secara umum adalah:

a. Sebagai Pendidikan nilai dan moral Pancasila serta Undang-Undang Dasar 1945

Dalam hal ini siswa diajarkan tentang nilai moral yang diperlukan seorang warga negara dalam kehidupan sebagai warga negara dan warga masyarakat.

b. Sebagai Pendidikan Politik

Siswa diajarkan bagaimana seharusnya mereka berpartisipasi dan berpikir positif terhadap pembangunan nasional. Selain itu siswa diharapkan memiliki kemampuan berpikir kreatif, dan inovatif terhadap berbagai 
permasalahan sosial, politik, ekonomi, dan budaya serta memeiliki rasa tanggung jawab, menghormati, dan menghargai aparat pemerintah.

c. Sebagai Pendidikan Kewarganegaraan

Siswa diharapkan bisa mengerti dan memahami hak dan kewajibannya dalam kehidupan bermasyarakat, dan bernegara,

d. Sebagai Pendidikan Hukum dan Kemasyarakatan

Siswa diharapkan melek terhadap hukum, yaitu sadar bahwa setiap tindakannya ada hukum dan peraturan yang mengaturnya.

\section{Kegiatan Belajar 2}

\section{Keterkaitan Pendidikan Kewarganegaraan dengan IPS}

A. Keterkaitan Antara Pendidikan Kewarganegaraan dan IPS serta Bagaimana Keterkaitan itu Terjadi

PKn dan IPS secara historis memiliki keterkaitan yang kuat. Bidang studi PKn menurut Kurikulum tahun 1994 diberi nama bidang studi Pendidikan Pancasila dan Kewaganegaraan adalah bagian dari bidang studi IPS.

Bidang studi PKn pengajarannya erat kaitannya dengan Pancasila dan UUD 1945 dan hal-hal yang menyangkut warga negara serta pemerintahan. Adapun disiplin Geografi, Ekonomi, dan Sejarah menjadi bidang studi IPS.

B. Konsep Pembelajaran Terpadu

Konsep pembelajaran terpadu dikenal dalam bentuk sederhana pada kurikulum 1968 disebut dengan pendekatan korelasi. Pendekatan korelasi yaitu menghubungkan dua atau lebih mata pelajaran saat menjelaskan suatu mata pelajaran. Misalnya saat menjelaskan konsep geografi, maka pada saat itu pula penjelasan konsep geografi tersebut dihubungkan.dengan konsep mata pelajaran lainnya, misalnya dihubungkan dengan wilayah kekuasaan dan lokasi ketika perang Diponegoro.

Tujuan dari pendekatan ini tidak lain adalah agar pengajaran yang disampaikan dapat lebih menarik bagi siswa menumbuhkan kreativitas mengajar guru, bahkan dapat menumbuhkan kerjasama antar siswa, juga antara guru dengan siswa, agar kegiatan lebih utuh dan terasa lebih nyata dan konkret. 
Ada beberapa karakteristik dari pembelajaran terpadu:

1. Berpusat pada anak

2. Memberikan pengalaman langsung kepada anak

3. Pemisahan antara bidang studi tidak begitu jelas.

4. Menyajikan konsep dari berbagai bidang studi dalam satu pembelajaran

5. Bersifat luwes

6. Hasil pembelajaran dapat berkembang sesuai dengan kebutuhan anak Ada beberapa kelebihan dari pembelajaran terpadu:

1. Pengalaman dan kegiatan belajar anak akan selalu relevan dengan tingkat perkembangan anak

2. Kegiatan yang dipilih lebih bermakna buat anak

3. Menumbuhkembangkan keterampilan anak

4. Meningkatkan keterampilan sosial anak.

5. Membahas permasalahan kekinian yang sering ditemui anak.

Oleh karena itu, guru diharapkan lebih professional yakni mampu dalam memadukan konsep dari berbagai mata pelajaran dalam sebuah pembelajaran, juga lebih kreatif dalam menampilkan konsep yang akan diajarkan.

C. Pendidikan Kewarganegaraan dalam Pendidikan Terpadu

Bidang studi Pendidikan Kewarganegaraan pada dasarnya sudah menerapkan pembelajaran terpadu, karena dilihat dari historisnya yang memiliki hubungan dengan bidang studi IPS. Ada beberapa hal yang menjadi dasar pertimbangan pembelajaran Terpadu:

1. Karakterististik anak sd

2. Konsep disiplin ilmu

3. Standar Kompetensi, Kompetensi Dasar, dan Indikator

4. Lingkungan Belajar Anak

\section{Kegiatan Belajar 3}

Hubungan Bidang Studi Pendidikan Kewarganegaraan dengan Mata Pelajaran lainnya. 
Bidang studi Pendidikan Kewarganegaraan selain dapat dihubungkan dengan mata pelajaran IPS, dapat juga dihubungan dengan bidang studi lainnya seperti Bahasa Indonesia, Matematika, IPA, dan Kesenian. Agar dapat terhubung, maka guru dapat menerapkan dengan menggunakan berbagai model pembelajaran seperti model connected, web, dan integrated.

Untuk model connectedbiasanya digunakan hanya yang berkaitandengan mata pelajaranitusendiri(hubunganintra). Sedangkan web dan integrateddapatdigunakanuntuk menghubungkan berbagai beberapa mata pelajaran dalam 1 kegiatan pembelajaran.

\section{Model Connected}

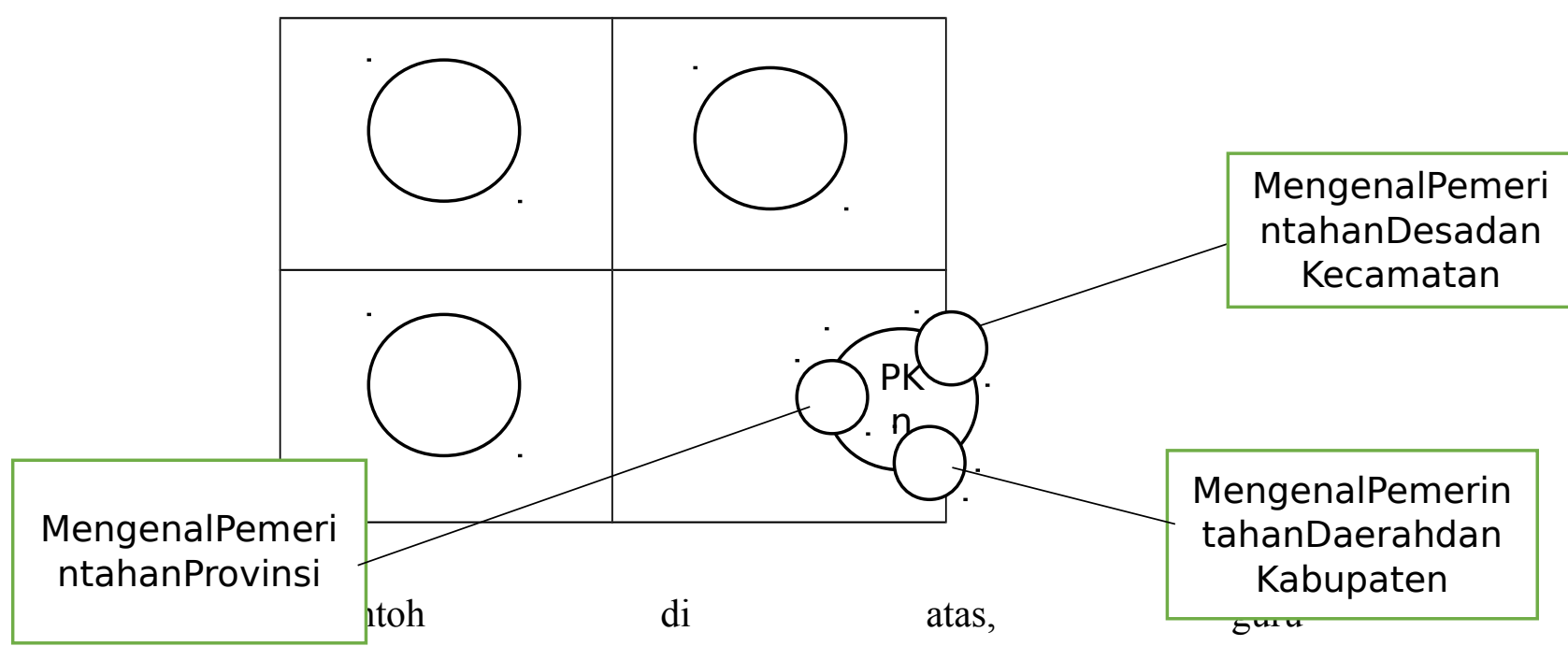

menghubungkankonsepantarapemerintahandesadankecamatan,

Pemerintahan

DaerahdanKabupaten, denganPemerintahanProvinsi. Ketiganyaberada di pembahasan yang berbeda, namundapatdigabungkandalamsatukonseppembahasan. Model Connectedmengharuskan guru mempelajarikonsepkonsepdariberbagaipembahasan/materidarimatapelajarantertentusehinggabisamenghubu ngkandalamsatukegiatanpembelajaran.

\section{Webbed Model}

Langkah-langkah yang ditempuh dalam model pembelajaran jaring laba-laba sebagai berikut :

1. Guru menyiapkan tema utama dan sub-tema yang telah dipilih dari beberapa standar kompetensi lintas mata pelajaran/ bidang Studi.

2. Mengidentifikasi indikator pada setiap kompetensi bidang pengembangan melalui tema dan sub-tema. 
3. Guru menjelaskan tema-tema yang terkait sehingga materinya lebih luas.

4. Guru memilih konsep, kegiatan atau informasi yang bisa mendorong belajar siswa.

Contoh:

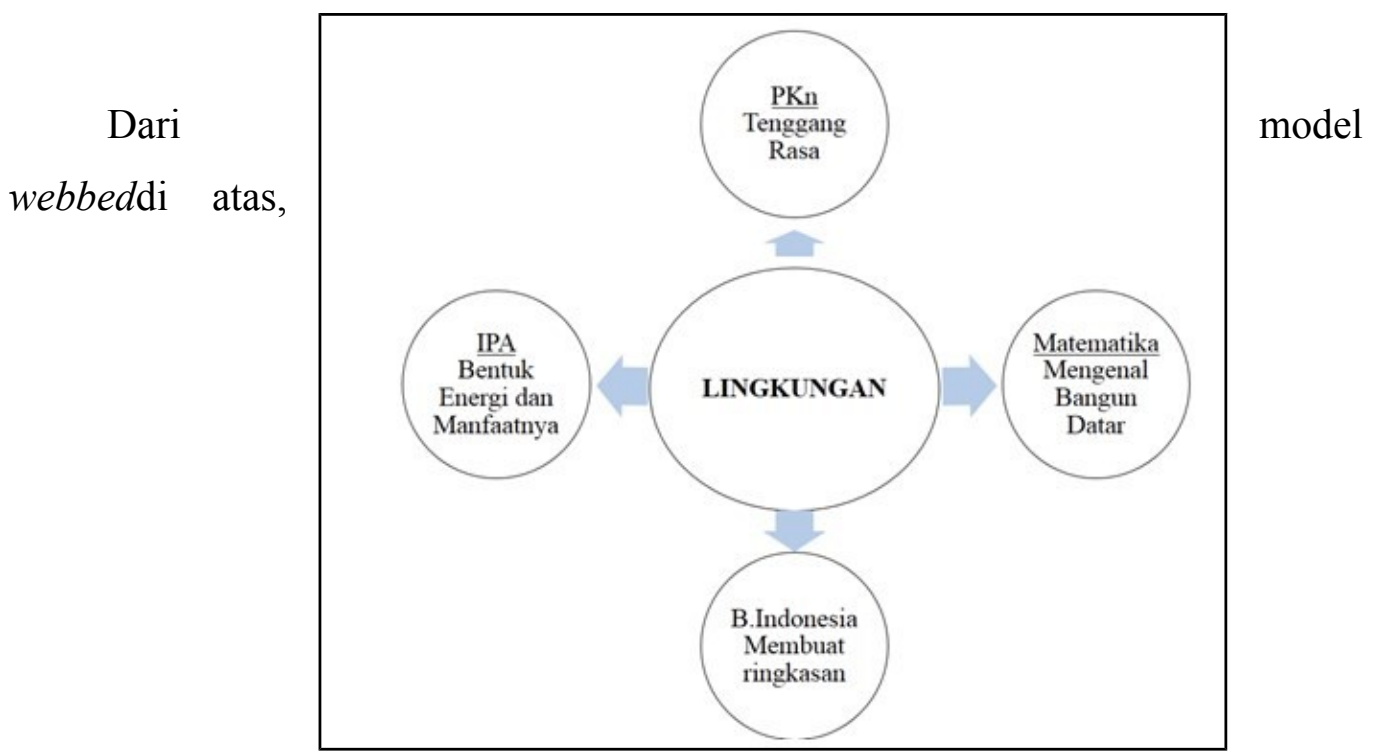

denganmenggunakanTemaLingkungan, dapatmenghubungkanberbagaimatapelajaran di antaranya IPA yang membahasBentukEnergidanManfaatnya yang ada di sebuahlingkungan, Bahasa Indonesia yang membahastentangmembuatringkasantentanglingkungan, PKnmembahastentangtenggang rasa dalamsebuahlingkungan, danMatematika yang membahastentangbenda-benda di sekitar yang berbentukbangundatar. Sehinggamemudahkananakmemahamikonsepdariberbagaimatapelajarandalamsebuahpe mbelajaran. 
Masing-masing model punyakelebihandankekurangan. Olehkarenaitu guru diharapkanbisamemilih model yang tepatdalampembelajarannyadisertaidenganmembuatinovasibaikitu media pembelajarannyasehinggamampumenggugahmotivasibelajarsiswa. 


\section{BAB III}

\section{PENUTUP}

Dari pembahasan di atas, makadapatdisimpulkanbahwa:

1. PendidikanKewarganegaraanmerupakan mata pelajaran yang memfokuskan pada pembentukan diri yang beragam dari segi agama, sosio-kultural, bahasa, usia, dan suku bangsa untuk menjadi warga negara Indonesia yang cerdas, terampil, dan berkarakter yang dilandasai Pancasila UUD 1945.Selainitupendidikankewarganegaraanmenuntut lahirnya warga negara dan warga masyarakat yang Pancasila, yang beriman dan bertakwa kepada Tuhan Yang Maha Esa yang mengetahui hak dan kewajibannya, menyadari pentingnya melaksanakan kewajiban-kewajibannya yang didasari oleh ksadaran dan tanggungjawabnya sebagai warga negara.

2. BidangstudiPKndan IPS merupakanbidangstudi yang membahastentangmasalahsosial. Bidang studi PKn pengajarannya erat kaitannya dengan Pancasila dan UUD 1945 dan hal-hal yang menyangkut warga negara serta pemerintahan. Adapun disiplin Geografi, Ekonomi, dan Sejarah menjadi bidang studi

IPS.

DalampengajarannyaPendidikanKewarganegaraanmembutuhkanmetodepembelajar anterpadusehinggadapat menumbuhkan kerjasama antar siswa, juga antara guru dengan siswa, agar kegiatan lebih utuh dan terasa lebih nyata dan konkret.

3. BidangstudiPendidikanKewarganegaraandapatdihubungkandenganmatapelajaranlai nnyadengan 3 model pembelajaranyaitu model connected, model webbed, dan model integrated

\section{Referensi}

Sulfemi, Wahyu Bagja dan Hilga Minati. (2018). Meningkatkan Hasil Belajar Peserta Didik Kelas 3 SD Menggunakan Model Picture And Picture dan Media Gambar Seri. JPSD. 4 (2), 228- 242 
Sulfemi, Wahyu Bagja \& Desmiati, Z. (2018). Model Pembelajaran Missouri Mathematics Project Berbantu Media Relief Experience dalam Meningkatkan Hasil Belajar Siswa. Pendas Mahakam: Jurnal Pendidikan Dasar, 3(3), 232245

Sulfemi, Wahyu Bagja. (2018). Pengaruh Disiplin Ibadah Sholat, Lingkungan Sekolah, dan Intelegensi Terhadap Hasil Belajar Peserta Didik Mata Pelajaran Pendidikan Agama Islam. Edukasi: Jurnal Penelitian Pendidikan Agama dan Keagamaan. 16 (2), 166-178.

Sulfemi, Wahyu Bagja, \& Nurhasanah. (2018). Penggunaan Metode Demontrasi Dan Media Audio Visual Dalam Meningkatkan Hasil Belajar Peserta Didik Mata Pelajaran IPS. Pendas Mahakam: Jurnal Pendidikan Dasar, 3(2), 151-158.

Sulfemi, Wahyu Bagja dan Setianingsih. (2018), Penggunaan Tames Games Tournament (TGT) Dengan Media Kartu Dalam Meningkatkan Hasil Belajar. Journal of Komodo Science Education (JKSE), 1 (1), 1-14

Sulfemi, Wahyu Bagja., \& Yuliana, D. (2019). Penerapan Model Pembelajaran Discovery Learning Meningkatkan Motivasi Dan Hasil Belajar Pendidikan Kewarganegaraan. Jurnal Rontal Keilmuan Pancasila dan Kewarganegaraan, 5(1), 17-30.

Sulfemi, Wahyu Bagja, dan Mayasari, Nova. (2019). Peranan Model Pembelajaran Value Clarification Technique Berbantuan Media Audio Visual Untuk Meningkatkan Hasil Belajar IPS. Jurnal Pendidikan 20 (1), 53-68

Sulfemi, Wahyu Bagja.(2019). Bergaul Tanpa Harus Menyakiti. Bogor : Visi Nusantara Maju.

Sulfemi, Wahyu Bagja. (2019). Menanggulangi Prilaku Bullying Di Sekolah. Bogor : Visi Nusantara Maju.

Sulfemi, Wahyu Bagja dan Yuliani, Nunung. (2019). Model Pembelajaran Contextual Teaching And Learning (CTL) Berbantu Media Miniatur Lingkungan Untuk Meningkatkan Hasil Belajar IPS. Edunomic : Jurnal Ilmiah Pendidikan Ekonomi Fakultas Keguruan Dan Ilmu Pendidikan. 7 (2) . 73-84.

Sulfemi, Wahyu Bagja (2019). Modul Pembelajaran Perundang-Undangan Pendidikan. Bogor : STKIP Muhammadiyah Bogor 